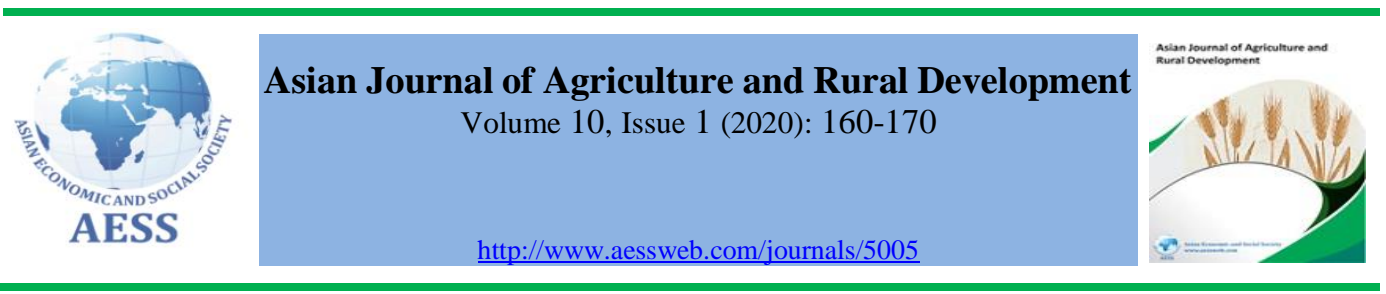

\title{
APPRAISAL OF BACKYARD FARMING AMONG HOUSEHOLDS: IMPLICATIONS FOR RURAL DEVELOPMENT AND FOOD SECURITY IN NIGERIA
}

Ovharhe, Oghenero ${ }^{\text {a }}$ Department of Agricultural Economics and Joseph $^{\text {a }}$, Extension, Delta State University, Asaba Campus, Achoja Felix Odemero a, Asaba, Delta State, Nigeria Okwuokenye Goddey Nigeria
Folunsho

Joe-James Uduak Oghenefejiro $^{\text {a }}$

\section{ARTICLE HISTORY: \\ Received: 03-Jan-2020 \\ Accepted: 11-Mar-2020 \\ Online Available: 06-Apr- 2020}

Keywords:

Household, Backyard farming, Livestock, Crops, Food security
- $\square$ drovharhe.oghenero@gmail.com; achojafelix@gmail.com (Corresponding author)

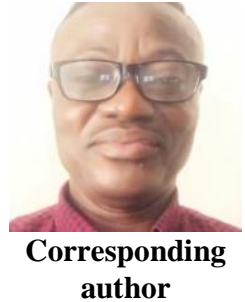

\begin{abstract}
This study investigates backyard farming and implications for food security in Nigeria. Purposive random sampling technique was used in this study to obtain a total of 80 respondents as sample size. Data were collected using structured questionnaire copies. Data generated were analyzed using descriptive and inferential statistics. The result showed that the respondents' mean age was 43 years. Women $(71 \%)$ were more involved in backyard farming than males (29\%). Identified mixtures of backyard household agricultural enterprises in order of preference by respondents were: vegetable growing $(88.75 \%)>$ cassava cropping $(76.25 \%)>$ yam cropping $(67.50 \%)>$ maize cropping $(52.50 \%)>$ plantain cropping $(46.25 \%)>$ poultry farming $(41.25 \%)$. A high satisfaction level was recorded in terms of farm yield $(\underline{x}=2.39)$ and food security $(\underline{x}=2.34)$. Extension workers' visits to farmers $(31.25 \%)$ were poor. Risk level was low $(\underline{x}=2.25)$. The result indicates a significant and positive relationship between farmers' adoption of improved crop varieties and access to extension services. The study recommends that advocacy should be scaled up for more family participation in backyard farming since it has the capacity for food security, income generation, and rural development.
\end{abstract}

\section{Contribution/ Originality}

The study derives significance from its contribution of empirical information to the existing literature in the area of backyard farming and its potentials for food security and rural development in Nigeria, and it highlighted one of the long-neglected but important aspects of farm family theory.

DOI: 10.18488/journal.1005/2020.10.1/1005.1.160.170

ISSN (P): 2304-1455/ISSN (E):2224-4433

How to cite: Ovharhe, Oghenero Joseph, Achoja Felix Odemero, Okwuokenye Goddey Folunsho and Joe-James Uduak Oghenefejiro (2020). Appraisal of backyard farming among households: implications for rural development and food security in Nigeria. Asian Journal of Agriculture and Rural Development, 10(1), 160-170. 


\section{INTRODUCTION}

Backyard farming is a compound type of farming located around the homestead for the production of varieties of crops and rearing of livestock for consumption, food security, and income generation. Cases of poverty and food insecurity among rural households in Nigeria have occupied central positions in both scientific and public debates in recent times. Backyard farming model for rural poverty alleviation and food security management has been widely accepted by rural farm families in Nigeria. It has the potential to improve households' cash economy and sustainability of the micro-environment (Achoja and Obodaya, 2019).

Homestead farmers are those individuals who cultivate crops and raise livestock around their houses (residence) or close to their residence. Backyard farming has the advantages of low start-up capital, low risk of theft, utilization of households' wastes and it is easy to manage and monitor. The backyard farm is, therefore, an important aspect of the households as it is usually the center of family lives (Onuebunwa and Adesope, 2006).

Household backyard farming contributes to food security by ensuring the availability of harvested produce and livestock which eventually will be used to feed family members often daily. Once a good understanding of household backyard farming practices, constraints and objectives are established and farmers can work on how to get improved varieties of crops.

The household backyard can be referred to as the very beginning of agriculture which has played a vital role in providing food and income for families. Household backyard farming is a small scale production system that involves the cultivation of land which may be around the household or within walking distances from the Farmers house. Backyard farming could be a mixed cropping type that encompasses vegetables, fruit, medicinal plants and livestock that serves as a source of income and food. Household backyard farming could be referred to as home farming. Chukwuji et al. (2001) viewed backyard farming as compound tree farming in mixture with other subsistence farming. The labour used is not compensated for. Home farming frequently uses family labour: men, women and children.

Home farming or backyard farming is always a small scale when the compound or residence is big enough to accommodate a good number of crops, wage labour may be hired to cultivate and maintain the farm, the household backyard farming may be vulnerable to a harsh environmental condition such as drought and flood just like the large scale farming which could be referred to as commercial farming irrespective of the small scale farmers activities demands a lesser amount of horticultural and agronomic knowledge, losses in crops and the negative implication can be reduced or even avoided when the farmers are empowered with knowledge and better skills.

Interviews with farmers have been able to reveal that kind of behavioral and economic incentives facing household farmers varies, even within the same city and culture. Backyard farming contributes to food security by ensuring the provision of food in the fresh form to satisfy the immediate calorie and nutritional needs of households (Ojo, 2009). Backyard farming is usually done on a small piece of plot in any convenient land area.

According to Oke (2014), backyard farming was initiated with a double purpose: household consumption and sales of surplus. This type of farming has been said to be a poverty eradication programme. Empowerment with better skills and knowledge of the small scale farmers or household farmers can be done with the help of agricultural extension officers.

Home farming has been recognized globally as a promising approach to enhance household food security and wellbeing. Based on rapid population growth, there is a need to increase food 
production and buffer stock with maximum use of the limited land area. Inoni (2007) opined that fish production requires any small size space for domestic and commercial intentions. Again, Mbanasor (2002), Ologbon and Ambali (2012) reaffirmed that poultry enterprises can flourish well as homestead basis among smallholder farmers.

Onuebunwa and Adesope (2006) identified challenges with household backyard farmers to include lack of finance, experienced high-interest rates on credit facilities and uncertainty of the right seed to use because of too many varieties of seed companies in the market. There should be the provision of information to all farmers either commercial or household farmers (Extension support service).

Backyard farmers are faced with the problem of how to allocate their labour and expenditure to maximize their welfare within a constraint of limited resources. At the conception of household backyard farming, farmers and the government believed that backyard farming would help the poor household or jobless individuals achieve food security and generate income through the production of food crops and sales of surplus produce. Impacts of backyard farming have not been evaluated as proof as to whether the social-economic status of farmers that benefitted from backyard farming has improved largely in competing with other farmers in resource management and farming business productivity.

The objectives of the study are to:

i. To describe the socio-economic characteristics of backyard farmers,

ii. To identify the improved crop varieties and livestock types adopted by backyard farmers,

iii. To evaluate the satisfaction level derived by backyard farmers,

iv. To ascertain the extension services rendered to backyard farmers,

v. To determine the risk types of backyard farms, and

vi. To identify the constraints associated with backyard farmers

The following hypothesis was tested in the study:

$\mathrm{H}_{\mathrm{O}}$ : There is no significant relationship between the presence of improved crop varieties and access to extension services.

\subsection{Related theoretical and empirical literature review in brevity}

Backyard farming is small -scale farming. Management of backyard farming is important in effective decision making, supervision and coordinating ability of the farmer. Effective backyard farming with good farm management practices involves the utilization of available resources of the environment to satisfy the household and maximize profit based on marketing.

Ngo et al. (1998) stated that the amount of profit made in any production either crop or livestock be it for consumption or income generation depends primarily on good management. There is a need for skilled manpower in small scale farming because whether it is large scale farming or not, they share the same objective and that is better yield production.

Backyard farming has been able to perform several functions that have influenced the socioeconomic status of an individual and the nation's development. Oke (2014) conceived backyard farming to mean a form of microenterprise which is a source of revenue for the unemployed, a supplemental income for the low-income boosters for the high-income earners. in every part of the country every family engages in agriculture in one area or the other, be it livestock farming or crop production which has helped to increase income levels The economic has proved that most families cannot afford the escalating cost of beef meat without breaking a sweat and this calls for alternative sources of meat in a human diet which is cheap, easy to manage. These alternative sources include fish farming, poultry farming, pig farming, etc. 
In Nigeria, there are different types of backyard farming. Backyard farming components are mix cropping: a mixture of cassava, plantain, maize, groundnut, cowpea, yam, cocoyam, sugarcane, fruit trees and medicinal plants; and mix farming: a mixture of crop and animal production, fisheries plus agro-forestry enterprises. Snail and mushroom farming fall into this sector.

\subsection{Conceptual framework of the study}

Backyard Farming is broadly categorized into mix cropping and mixed farming including varieties of crop, livestock types, and fisheries in well-organized farming patterns. Many households practice different types of backyard farming cutting across sole cropping, sole animal husbandry, sole aquaculture, a mixture of crops, a mixture of livestock, complete mixture of crops, livestock and/or aquaculture. Upon establishment of a backyard farm at whatever levels, the onus lies on the backyard farm practitioner to identify and adopt the desired farming practices. Based on the farming practices adopted; if grounded on the best practices principles, the satisfaction level is guaranteed. Otherwise, worst farming practices tend to dissatisfaction level (Figure 1) which is detrimental to the purpose of backyard farm establishment. Risk and constraint issues involved in backyard farming when well managed are associated with best agricultural practices (BAPs) which lead to backyard farm goals achievement and satisfaction. On the contrary, worst agricultural practices (WAPs) are congruent to the non-adoption of technological advancement as communicated by extension workers. BAPs and WAPs are pulling and pushing forces of backyard farming respectively. While BAPs tend to pull backyard farming to success and satisfaction, WAPs tend to push it to failure and dissatisfaction.

\section{MATERIALS AND METHODS}

The study was conducted in 5 local government areas in Delta State, Nigeria. The state consists of 25 local government areas. The global position system (GPS) $6.5 ; 6$ coordinates are between $5^{\circ} 30 \mathrm{~N}$, $6^{\circ} 00 \mathrm{t}, 5^{\circ} 30 \mathrm{~N}, 6^{\circ} 00 \mathrm{E}$. The land area is between $17698 \mathrm{~km} 2(6833 \mathrm{sqm})$, area. The local government areas were Ughelli North, Ughelli South, Ika East, Isoko South and Patani.

\subsection{Sampling technique and sampling size}

A two-stage sampling procedure was adopted for the study. The First stage was the use of simple random sampling techniques to select 5 communities out of the 5 local government areas in the study area. The second stage was the purposive random sampling of 16 respondents from each of the 5 communities to obtain a total sample size of 80 respondents. An equal sample size of 16 respondents per community was considered appropriate for the study backyard farming system is relatively homogenous across the State. Primary data were collected using structured questionnaires that were administered by the research team.

\subsection{Methods of data analysis}

Objectives one which referred to the socio-economic characteristics of respondents was achieved using descriptive statistics such as frequency counts, means and percentages. Objective two was achieved through respondent's identification of the improved crop varieties and livestock types adopted in backyard farming as indicated in a check. Objective three and five were achieved through the use of a 4point Likert-type scale to indicate a level of satisfaction and risk levels respectively (nil $=0$, low $=1$, medium $=2$, high $=3$ ). The average of the corresponding weights $(0$ $+1+2+3) / 4=1.5$ was used as the assumed cut-off mark. This implies that items with values $\geq$ 1.5 were considered satisfactory. While items with values $<1.5$ were rated not satisfactory. On the contrary, as applicable to risk levels, using the same scale, items with values $\geq 1.5$ are considered risk factors, while items with values $<1.5$ are not risky. Objective four based on extension activities was achieved using binary response (yes or no) from listed interrogation concerning extension activities. Objective six was achieved using a Four-Type Likert scale consisting of strongly disagree (1), disagree (2), agree (3) and strongly agree (4). The mean corresponding 
weight was $(1+2+3+4) / 4=2.5$. Hence, 2.5 was used as the cut-off mean to judge the degree of seriousness of identified constraints $(\underline{x} \geq 2.5)$ or a lesser degree of seriousness $(\underline{x}<2.5)$. For each ranging scale used, a grand mean value was generated such that the sum of means was divided by the number of items under consideration.

The test of the hypothesis $\left(\mathrm{H}_{0}\right)$ was analyzed with the use of the Pearson chi-square method in a software package.

\section{RESULTS AND DISCUSSION}

\subsection{Socio-economic characteristics of the respondents}

The socio-economic characteristics of the respondent of the respondents are discussed under the following; age, sex, marital status, household size, and educational status. The ages of the respondents in the study (Table 1) showed that most ranges from 45-54 years with a mean of 43 years. Data on respondent gender revealed that $29 \%$ of respondents were male while $71 \%$ were female. This suggests that women were involved in backyard farming more than males in the study area. Okwuokenye and Ovharhe (2019) acknowledged that women were more into arable cropping than permanent cropping in Delta South Agricultural Zone of Delta State, Nigeria. Married respondents were $89 \%$, and the single was $11 \%$.

The different household sizes of various respondents revealed that $44 \%$ of the respondents were between 2-4 persons, $49 \%$ of the respondents were between 5-7 persons, $3 \%$ of the respondents had 8-10 persons, $1 \%$ of the respondents had between 11 persons and above. The mean household size was 5 persons per household. Ovharhe (2019) reported a similar result on a household survey in the Niger Delta.

Table 1: Socio-economic characteristics of Respondents $(\mathbf{n}=\mathbf{8 0})$

\begin{tabular}{lccc}
\hline Parameters & Frequency & Percentage (\%) & Mean/ Mode \\
\hline Age & 3 & 3.25 & \\
$15-24$ & 7 & 8.25 & \\
$25-34$ & 31 & 38.75 & 42.5 \\
$35-44$ & 34 & 42.5 & \\
$45-54$ & 5 & 6.25 & \\
$55-64$ & & & Female \\
Gender & 23 & 28.75 & \\
Male & 57 & 71.25 & Married \\
Female & & & \\
Marital Status & 9 & 11.25 & \\
Single & 71 & 88.75 & \\
Married & & & \\
Household Size & 35 & 43.75 & \\
$2-4$ & 39 & 48.75 & \\
$5-7$ & 3 & 3.75 & \\
$8-10$ & 1 & 1.25 & \\
$11-13$ & 1 & 1.25 & \\
$14-16$ & 1 & 1.25 & \\
$17-19$ & & & \\
\hline
\end{tabular}

Source: Field Survey, 2019

\subsection{Improved varieties and type of backyard farm}

Result in Table 2 showed a profile of backyard farming enterprises such that improved varieties, stocks, and types of backyard farming ranked hierarchically as follows: vegetable growing 
(88.75\%), cassava cropping (76.25\%), yam cropping (67.50\%), maize cropping $(52.50 \%)$, plantain cropping $(46.25 \%)$, poultry farming $(41.25 \%)$, okra cropping $(27.50 \%)$, potato farming $(22.50 \%)$, aquaculture $(17.50 \%)$, piggery $(13.75 \%)$, goat keeping $(10.00 \%)$, snail farming $(5.00 \%)$ and rabbitry $(2.50 \%)$. Based line of fifty percent was used to judge the prevalence of backyard farming enterprises in the study area. As a result, by preference, vegetable growing > cassava cropping > yam cropping > maize cropping. These four enterprises are mostly found and utilized by resident farmers in the study area. In another household economic analysis survey, Oladunni and Fatuase (2014) asserted that improved varieties yielded more in backyard farming methods. Hence, farmers partner with extension workers to have access to improved input stocks whether in crop or animal husbandry.

Table 2: Respondents' types of backyard farming

\begin{tabular}{lccc}
\hline Enterprise & Yes* $^{*}$ & Percentage (\%) & Rank \\
\hline Vegetable growing & 71 & 88.75 & 1 \\
Cassava cropping & 61 & 76.25 & 2 \\
Yam cropping & 54 & 67.50 & 3 \\
Maize cropping & 42 & 52.50 & 4 \\
Plantain cropping & 37 & 46.25 & 5 \\
Poultry farming & 33 & 41.25 & 6 \\
Okra cropping & 22 & 27.50 & 7 \\
Potato farming & 18 & 22.50 & 8 \\
Aquaculture & 14 & 17.50 & 9 \\
Piggery & 11 & 13.75 & 10 \\
Goat keeping & 8 & 10.00 & 11 \\
Snail farming & 4 & 5.00 & 12 \\
Rabbitry & 2 & 2.5 & 13 \\
\hline
\end{tabular}

Source: Field Survey, 2019 (*Multiple responses)

\subsection{Level of satisfaction}

Result in Table 3 shows that the mean level of satisfaction of farmers involved in backyard farming experienced high satisfaction level in available water supply for farming water supply $(\underline{x}=2.48)$, farm yield $(\underline{x}=2.39)$,food availability $(\underline{x}=2.34)$, organic manure usage $(\underline{x}=2.30)$, market adequacy $(\underline{x}=2.18)$, farm tools usage $(\underline{x}=1.89)$, improved seeds provision $(\underline{x}=1.54)$, extension training $(\underline{x}=1.14)$, inorganic manure usage $(\underline{x}=1.10)$ and storage techniques $(\underline{x}=0.99)$. In line with the results, only extension training, inorganic manure usage, and storage techniques adoption that was below $(\underline{x}<1.5$.). This was used as a baseline judgment of not satisfied. Satisfaction grand mean of 1.84 was generated $(\underline{x}>1.5$.). This implies that generally, household members were satisfied with backyard farming in the study area. Ovharhe et al. (2016) in a Fadama Survey in Delta State discovered that farmers were assisted with Fadama inputs and assets experienced high yield in backyard farm practices with ease to market their product.

Table 3: Respondents' level of satisfaction $(n=80)$

\begin{tabular}{lccccc}
\hline Items & Nil (0) & Low(1) & Medium(2) & High (3) & Mean \\
\hline Water supply & 2 & 5 & 26 & 47 & 2.48 \\
Farm yield & 0 & 0 & 49 & 31 & 2.39 \\
Food availability & 2 & 5 & 37 & 36 & 2.34 \\
Organic manure usage & 4 & 10 & 24 & 42 & 2.30 \\
Market Adequacy & 1 & 8 & 47 & 24 & 2.18 \\
Farm tools usage & 1 & 24 & 39 & 16 & 1.89 \\
Improved Seeds provision & 7 & 34 & 28 & 11 & 1.54 \\
Extension Training & 17 & 38 & 22 & 3 & 1.14 \\
\hline
\end{tabular}




\begin{tabular}{llllll}
\hline Inorganic manure usage & 17 & 43 & 15 & 5 & 1.10 \\
Storage techniques & 21 & 42 & 10 & 9 & 0.99 \\
Grand mean $=1.84$ & & & & & \\
\hline
\end{tabular}

Source: Field Survey, 2019

\subsection{Extension activities rendered to farmers}

Results in Table.4 outlined the extensive activities partook by farmers. Noticeable observations were seen as a decision making on farming enterprise $(88.75 \%$ ), knowledge sharing among neighbouring farmers $(85.00 \%)$, BAPs $(66.25 \%)$, extension workers visit farmers $(31.25 \%)$, access to television agric-show $(27.50 \%)$, access to radio agric-show $(22.50 \%)$, access to demo plot (21.25\%), (access to internet services $(17.50 \%)$, extension- farmer phone contact $(11.25 \%)$ and farmers' visit to extension offices $(6.52 \%)$, Specifically, backyard farmers in the study area were mostly involved in three items which were above fifty percent: decision making on farming enterprise, knowledge sharing among neighbouring farmers and BAPs. Invariably, these might have contributed to some levels of success recorded in backyard farming among households. In a separate study, it was reported that of all sources of information on vegetable production, the information needs of farmers were mostly met by farmers' personal efforts in knowledge search (Alakpa et al., 2016). Benard et al. (2014) reported that farmers in Tanzania did not make use of the internet and public information center due to low awareness of the importance of modern technologies to access agricultural information. Efforts are needed to bring the extension workers to the doorsteps of backyard farmers to perform their tasks to increase productivity among backyard farmers.

Table 4: Respondents' involvement in extension activities

\begin{tabular}{lccc}
\hline Items & Yes* & Percentage (\%) & Rank \\
\hline Decision making on a farming enterprise & 71 & 88.75 & 1 \\
Knowledge sharing among neighbouring farmers & 68 & 85.00 & 2 \\
BAPs & 53 & 66.25 & 3 \\
Extension workers visit farmers & 25 & 31.25 & 4 \\
Access to television agric-show & 22 & 27.50 & 5 \\
Access to radio agric-show & 18 & 22.50 & 6 \\
Access to demo plot & 17 & 21.25 & 7 \\
Access to internet services & 14 & 17.50 & 8 \\
Extension- Farmer phone contact & 9 & 11.25 & 9 \\
Farmers visit extension offices & 5 & 6.52 & 10 \\
\hline
\end{tabular}

Source: Field Survey, 2019

Note: * Multiple responses

\subsection{Level of risk in backyard farming}

Using the cut-off point of ( $\underline{x} \geq 1.5$ for high risk), values obtained in Table 5, it showed that the level of risk in backyard farming is highest with pest attack $(\underline{x}=2.25)$ only. Others have lesser risk such as theft incidence $(\underline{x}=1.21)$, yield spoilage $(\underline{x}=1.15)$, marketing $(\underline{x}=1.05)$ and farm supervision $(\underline{x}$ $=1.00)$ accordingly. In managing the risk level of high incidence attacks of pests, Khan (2013) opined that extension agents can assist by regular visits, training and guiding farmers in decision making. Thus, packaging programmes with a focus on integrated pest management (IPM) will reduce the incidence of pest invasion and subsequently, increase agricultural productivity among backyard farm practitioners. There is a need to increase tactics on backyard farm surveillance as this will help to reduce theft of backyard farm produce. 
A risk level grand mean of 1.33 was generated $(\underline{x}<1.5$.). It is hereby deduced that backyard farming is not a highly risky enterprise in Delta State. As a result, folks are advised to venture into backyard farming. This is a giant stride for food security alternatives.

Table 5: Respondents level of risk in backyard farming

\begin{tabular}{lccccc}
\hline Indicators & Nil (0) & Low(1) & Medium(2) & High(3) & Mean \\
\hline Pest attack & 4 & 12 & 24 & 40 & 2.25 \\
Theft incidence & 21 & 30 & 20 & 9 & 1.21 \\
Yield spoilage & 23 & 31 & 17 & 9 & 1.15 \\
Marketing & 22 & 38 & 8 & 10 & 1.05 \\
Supervision & 26 & 34 & 14 & 6 & 1.00 \\
Grand mean $=1.33$ & & & & & \\
\hline
\end{tabular}

Source: Field Survey, 2019

\subsection{Constraints to backyard farming}

Results in Table 6 revealed the constraints to backyard farming and were ranked accordingly: nonlinkage to agricultural funds $(\underline{x}=3.30)$, pest attack incidence $(\underline{x}=3.20)$, poor access to extension activities $(\underline{x}=3.08)$, poaching $(\underline{x}=2.31)$, low farm inputs availability $(\underline{x}=2.19)$, insufficient farm land area $(\underline{x}=1.78)$, irrigation difficulty $(\underline{x}=1.60)$, food scarcity $(\underline{x}=1.51)$ and flooding $(\underline{x}=1.36)$. The most serious constraints in backyard farming were non-linkage to agricultural funds, pest attack incidence and poor access to extension activities. Eventually, addressing these constraints would boost agricultural produce among backyard farmers in Delta State of Nigeria.

Ovharhe et al. (2016) in a Fadama Survey in Delta State discovered that insufficient funding is a constraint in farmers' development. A constraint grand mean of 2.26 was generated $(\underline{x}<2.5$.). Here is an implication that the overall constraints affecting backyard farming are not too serious, such that they could affect backyard farming productivity. They are manageable in BAPs.

Table 6: Respondents' degree of constraints in backyard farming

\begin{tabular}{lccccc}
\hline Items & $\begin{array}{c}\text { Strongly } \\
\text { disagree (1) }\end{array}$ & $\begin{array}{c}\text { Disagree } \\
\text { (2) }\end{array}$ & Agree (3) & $\begin{array}{c}\text { Strongly } \\
\text { agree(4) }\end{array}$ & Mean \\
\hline Non-Linkage to agricultural funds & 6 & 8 & 22 & 44 & 3.30 \\
Pest attack incidence & 4 & 10 & 32 & 34 & 3.20 \\
Poor access to extension activities & 8 & 16 & 18 & 38 & 3.08 \\
Poaching & 17 & 30 & 24 & 9 & 2.31 \\
Low farm inputs availability & 3 & 31 & 37 & 9 & 2.19 \\
Insufficient farm land area & 40 & 28 & 2 & 10 & 1.78 \\
Irrigation difficulty & 45 & 27 & 3 & 5 & 1.60 \\
Food scarcity & 51 & 21 & 4 & 4 & 1.51 \\
Flooding & 61 & 12 & 4 & 3 & 1.36 \\
Grand mean =2.26 & & & & & \\
\hline
\end{tabular}

Source: Field Survey, 2019

Table 7 shows the result of the relationship between the growth of improved crop variety and access to extension services. From the result the value of Pearson chi-square $=3.810$, continuity correlation $=2.743$, livelihood ration $=4.059$, linear by linear association $=3.762$, number of valid cases $=80$

The chi-square result revealed that at $5 \%$ test of significance $\mathrm{P}>0(0.046)$. This implies that the significant relationship exists between variables hence the null hypothesis was rejected with the conclusion that few farmers with improved crop varieties had access to extension services. That is 
to say the more the availability of extension workers rendering services to backyard farmers, the more the farm productivity in backyard farming. Alakpa et al. (2016) had a similar experience such that women in vegetable production increased in productivity due to farming needs satisfaction by extension workers.

Table 7: Cross-tabulation information for chi-square computation

\begin{tabular}{|c|c|c|c|c|c|}
\hline \multirow{2}{*}{ Parameter } & & & \multicolumn{2}{|c|}{ Type of vegetable crop grown } & \multirow[b]{2}{*}{ Total } \\
\hline & & & Traditional & Improved & \\
\hline \multirow{6}{*}{$\begin{array}{l}\text { Do you obtain } \\
\text { information } \\
\text { from extension } \\
\text { workers } \\
\text { programme }\end{array}$} & No & Count & 11 & 3 & 14 \\
\hline & & Expected Count & 7.7 & 6.3 & 14.0 \\
\hline & & $\%$ of Total & $13.8 \%$ & $3.8 \%$ & $17.5 \%$ \\
\hline & Yes & Count & 33 & 33 & 66 \\
\hline & & Expected Count & 36.3 & 29.7 & 66.0 \\
\hline & & $\%$ of Total & $41.2 \%$ & 41.2 & $82.5 \%$ \\
\hline \multirow[t]{3}{*}{ Total } & & Count & 44 & 36 & 80 \\
\hline & & Expected Count & 44.0 & 36.0 & 80.0 \\
\hline & & $\%$ of Total & $55.0 \%$ & $45.0 \%$ & $100.0 \%$ \\
\hline
\end{tabular}

Source: Field Survey, 2019

Table 8: Chi-square computation result

\begin{tabular}{lccccc}
\hline Parameter & Value & Df & $\begin{array}{c}\text { Asymp sig } \\
\text { (2-sided) }\end{array}$ & $\begin{array}{c}\text { Exact sig } \\
\text { (2-sided) }\end{array}$ & $\begin{array}{c}\text { Exact sig } \\
\text { (1-sided) }\end{array}$ \\
\hline $\begin{array}{l}\text { Pearson chi-square } \\
\begin{array}{l}\text { Continuity correction } \\
\text { Likelihood ratio }\end{array}\end{array}$ & 3.810 & 1 & 0.051 & & \\
$\begin{array}{l}\text { Fisher's exact test } \\
\text { Linear-by-linear }\end{array}$ & 4.059 & 1 & 0.098 & & \\
$\begin{array}{l}\text { association } \\
\text { N of Valid cases }\end{array}$ & 3.762 & 1 & & 0.075 & 0.046 \\
\hline
\end{tabular}

Note: Significant at $5 \%$ level

\section{CONCLUSION}

Based on the finding of this research, it is believed that backyard farming has a great impact on providing food for households and its locality. The study showed that females dominated household backyard farming with the majority married. Of the thirteen agricultural enterprises surveyed, the most prevalent backyard farming types were vegetable growing, cassava cropping, yam cropping and maize cropping with subsequent high levels of satisfaction recorded. They displayed self-help efforts in decision making and knowledge sharing which led to the best agricultural practices at their levels besides minimal extension support to very few farmers. Only pest attack incidence was considered at a high level of risk factors. Serious degrees of constraints were noticeable in nonagricultural fund supports, pest attack incidence and poor access to extension workers.

The following recommendations are necessary to add values to household backyard farming:

Since married females dominate household backyard farming, there should be attempts to convince the household occupants who are youth to partake in backyard farming. The policy implication here is that every household should embark on backyard farming as a measure of food security, income generation, and recreation activity.

i. Besides the prevalent backyard farming enterprises, efforts should be geared towards little backyard fruit tree planting for bigger premises with space. This will increase fruit 
availability, act as a shade, support wind-breaks and carbon sequestration for environmental sustainability. Thus, policy implication should be centered on 'operation one household, one fruit tree'. Again, this policy will constitute an addendum to the mitigation profile of climate change in Delta State and Nigeria at large.

ii. The attitudinal self-help postures of backyard farmers' involvement in decision making and knowledge sharing could be improved upon if extension workers are adequately mobilized to reach backyard farmers. Invariably, this must improve and uphold the best agricultural practices in the localities. In essence, existing policies on reaching farmers in the field should be redefined to include household backyard farmers since they are part of agricultural productivity.

iii. In controlling pest attack incidence, a stakeholder synergy is desirable with awareness creation and capacity building. Policy implications are needed for integrating pest management among neighborhoods. This will drastically reduce the migration of pests, improve environmental friendliness and food security.

iv. The issue of inadequate funding as mentioned by backyard farm practitioners as a serious constraint could be best handled by government policies inclusion and introduction of 'best backyard farmer award' concerning stated terms and conditions. This will act as an incentive to backyard farm practitioners and avenues for new entrants in the venture.

\footnotetext{
Funding: This study received no specific financial support.

Competing Interests: The authors declared that they have no conflict of interests.

Contributors/Acknowledgement: All authors participated equally in designing and estimation of current research.

Views and opinions expressed in this study are the views and opinions of the authors, Asian Journal of Agriculture and Rural Development shall not be responsible or answerable for any loss, damage or liability etc. caused in relation to/arising out of the use of the content.
}

\section{References}

Achoja, F. O., \& Obodaya, O. (2019). Backyard orchard ownership: implications for rural poverty alleviation and food security management in Nigeria. KSU Journal of Agriculture and Nature, 22(2), 456-464. DOI: 10.18016/ksutarimdoga.vi.546913.

Alakpa, S. O. E., Okonedo-Okojie, D. U., \& Ovharhe, O. J. (2016). Information needs assessment of women involved in vegetable production in Edo State, Nigeria. Research and Reviews: Journal of Ecology, 5(1), 1-9.

Benard, R., Dulle, F., \& Ngalapa, H. (2014). Assessment of information needs of rice farmers in Tanzania. A case study of Kilombero District, Morogoro.

Chukwuji, C. O., Sagwu, C. N., \& Inoni, O. E. (2001). Potential benefits of rural compound food tree crops in Delta State. International Journal of Environment and Development, 5(2), $12-19$.

Inoni, O. E. (2007). Allocative efficiency in pond fish production in Delta State, Nigeria. A production function Approach. Agricultural Tropical and Subtropical, 4.4(4), 127-134.

Khan, D. (2013). Managing Risk in Farming. Farm management extension guide by FAO. www.fao.org/publication.

Mbanasor, J. A. (2002). Resource use pattern among poultry enterprises in Abia State, Nigeria. Nigeria Journal of Animal Production, 29, 64-70

Ngo, D. A., Fronny, G. W., \& Babji, A. S. (1998). Characteristics of egg from young and old laying hens. Poultry Science, 62(4), 718-720.

Ojo, S. O. (2009). Backyard farming. Nigeria Journal of Human Ecology, 28(2), 127-132.

Oke, J. I. (2014). Gross margin analysis of backyard farming in Osun State, Nigeria. International Journal of Agricultural Economics and Rural Development, 6(1), 67-74. 
Okwuokenye, G. F., \& Ovharhe, O. J. (2019). Evaluation of the agricultural development programme in delta south agricultural zone: a case study of the extension sub-unit of the programme. Taraba Journal of Agricultural Research, 5(2), 41-48.

Oladunni, M. E., \& Fatuase, A. I. (2014). Economic analysis of backyard faming in akoko north west local government area of Ondo State, Nigeria. Global Journal of Biology, Agriculture and Health Science, 3(1),141-147.

Ologbon, O. A. C., \& Ambali, O. I. (2012). Poultry enterprise combination among small scale farmers in Ogun State Nigeria. A technical efficiency approach. Journal of Agriculture and Veterinary Science, 4, 7-15.

Onuebunwa, B. N., \& Adesope, O. M. (2006). Contributions of women and children to backyard farm labour in ikeduru area of Imo state, Nigeria. International Journal of Natural and Applied Sciences, 2(3), 189-192. doi.org/10.4314/ijonas.v2i3.36086.

Ovharhe, O. J. (2019). Determinants of the socioeconomic profile of Fadama III Project beneficiaries in three States of Niger Delta area of Nigeria. International Journal of Agricultural Science, 4, 29-34.

Ovharhe, O. J., Oyibo, O., \& Alakpa, S. O. E. (2016). Appraisal of Fadama III beneficiaries levels of satisfaction in the operation, utilization and maintenance of rural infrastructure in Delta State, Nigeria. Journal of Agriculture and Food Environment, 3(2), 32-40. 